\title{
Rapamycin therapy for neonatal tuberous sclerosis complex with cardiac rhabdomyomas: A case report and review
}

\author{
SHANSHAN MAO ${ }^{1}$, QI LONG ${ }^{2}$, HUIJIA LIN ${ }^{3}$ and JINLING LIU ${ }^{4}$ \\ Departments of ${ }^{1}$ Neurology, ${ }^{2}$ Clinical Nutrition, ${ }^{3}$ Neonatology and ${ }^{4}$ Pulmonology, The Children's Hospital, \\ Zhejiang University School of Medicine, Hangzhou, Zhejiang 310052, P.R. China
}

Received September 19, 2016; Accepted July 11, 2017

DOI: $10.3892 / \mathrm{etm} .2017 .5335$

\begin{abstract}
Tuberous sclerosis complex (TSC) is an autosomal dominant genetic disease that varies greatly in its expression. The current study reports a novel case of TSC caused by a TSC 2 mutation (TSC2c.1642_1643insA or TSC $2 p$. K549fs X589), in which multiple cardiac rhabdomyomas were detected by fetal echocardiography in week 31 of pregnancy. The infant was delivered successfully; however, seizures began 16 days following birth. Subsequent genetic tests confirmed a diagnosis of TSC. Rapamycin treatment resulted in regression of cardiac rhabdomyomas and controlled seizures. The current study demonstrates the value of fetal echocardiography in the diagnosis of TSC and suggests that inhibition of the mammalian target of the rapamycin (mTOR) signaling pathway may be considered as a potential antiepileptogenic therapy for neonatal TSC. In addition, it was demonstrated that rapamycin treatment was therapeutically beneficial for preventing disorders caused by abnormal mTOR signaling, such as cancer. According to the literature, cardiac rhabdomyomas, seizures and skin lesions are well established markers for TSC in neonates. MRI scans of the brain and genetic screening of TSC1 and TSC2 genes may facilitate an early diagnosis of TSC.
\end{abstract}

\section{Introduction}

Tuberous sclerosis complex (TSC) is an autosomal dominant genetic disease with an incidence of 1 in 6,000 and its symptoms include seizures, mental retardation, skin lesions and the formation of hamartomas in multiple organs, including the heart, brain, eye and kidney (1). Mutations in one of the two tumor suppressor genes TSC1-9q34 and TSC2-16p13.3 are responsible for TSC (2). The absence of clinical features

Correspondence to: Dr Jinling Liu, Department of Pulmonology, The Children's Hospital, Zhejiang University School of Medicine, 3333 Binsheng Road, Hangzhou, Zhejiang 310052, P.R. China E-mail: horseliu@126.com

Key words: cardiac rhabdomyomas, mutation, neonatal tuberous sclerosis, seizures during the neonatal period makes the diagnosis of TSC difficult. Neonatal ultrasound and cerebral magnetic resonance imaging (MRI) may be used to detect hamartomas in the heart and brain (3). Additionally, genetic mutation analysis means that the risk of a couple conceiving a child with TSC can be determined prior to pregnancy (4). Shepherd et al (5) analyzed 355 cases of TSC and reported that the mortality rate is $13.8 \%$.

Medication and surgery are the major treatment methods for TSC $(6,7)$. Vigabatrin, an antiepileptic medicine, was approved in 2009 and recommended as a first-line drug for TSC- associated infantile spasms by 2012 (8). In addition, adrenocorticotropic hormone was approved to treat infantile spasms in 2010 (9). Everolimus is applied for brain (subependymal giant cell astrocytoma) and kidney (renal angiomyolipoma) tumor treatment in children with TSC (10) and has also been demonstrated to be effective for TSC-epilepsy treatment (11). In 2017 votubia was recommended by the European Commission as a treatment for refractory partial-onset seizures in patients with TSC (12). Canpolat et al (13) demonstrated that rapamycin effectively controls epilepsy without causing any marked side effects in children with TSC.

The current study describes a case of multiple cardiac rhabdomyomas confirmed by routine echocardiogram screening in week 31 of pregnancy. The infant experienced seizures in the neonatal period ( 2 weeks of age), which is earlier than previously reported cases in which the onset was 1 month of age (14). Genetic mutation analysis revealed a novel mutation in TSC2. The clinical presentation and final outcome of neonatal TSC is discussed in the current study.

\section{Case report}

The mother of the infant in the current case report was a 29-year-old female (gravida 2, para 0) who experienced an uncomplicated pregnancy until week 31 of gestation. A routine echocardiography examination revealed multiple substantial hyperechoic masses in the ventricular wall of the fetus, suggesting a diagnosis of cardiac rhabdomyomas. A male infant weighing $3 \mathrm{~kg}$ was successfully delivered in week 39 of pregnancy. At 23 days old, the infant was admitted to the Emergency Department of the Children's Hospital, Zhejiang University School of Medicine (Hangzhou, China) in January 2016. The infant had undergone a series of active seizures in the week prior to admittance. Seizure episodes 

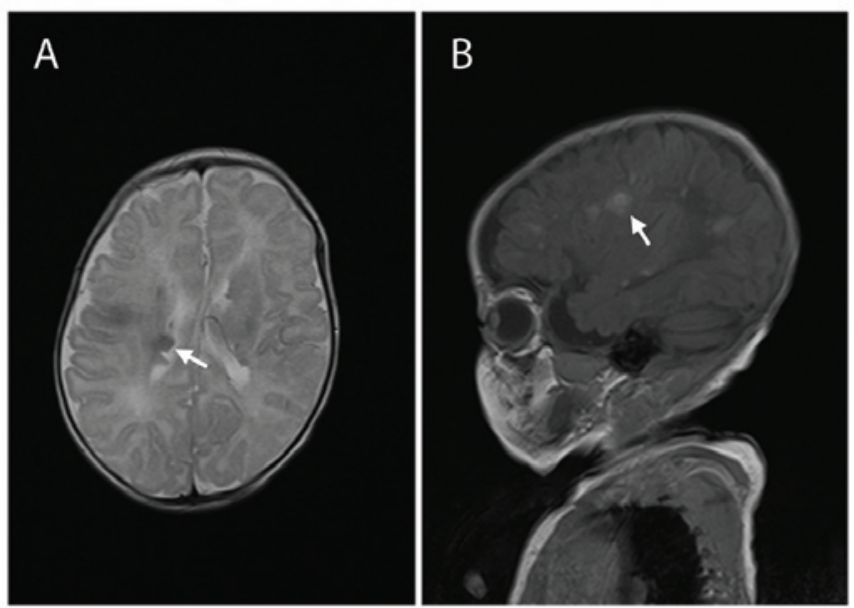

Figure 1. Neonatal (23-day-old) brain MRI. (A) Axial plane and (B) sagittal plane MRI images of a neonate with tuberous sclerosis complex at the first visit. The subependymal nodule is indicated by an arrow. MRI, magnetic resonance imaging.

were characterized by paroxysmal jittery limbs followed by the passing of urine. Each episode lasted 5-10 sec and was not accompanied by fever. The parents of the infant were healthy and had no history of TSC. The patient's family denied a history of epilepsy, mental retardation and behavioral problems.

Physical examination revealed a small number of hypomelanotic macules on the skin on the chest and back of the infant. The results of the neurological (including physiological reflex) and cardiovascular (heart rate, $124 \mathrm{bpm}$; blood pressure, $74 / 40 \mathrm{mmHg}$ ) examinations were normal. MRI scans of the brain identified subependymal nodules and subcortical tubers (Fig. 1), which are two distinct features of TSC. Echocardiography revealed hyperechoic masses with clear borders and uniform echoes, measuring $1.06 \times 0.89$ and $1.77 \times 1.68 \mathrm{~cm}$ in the left atrium and the outlet of the right ventricle, respectively, verifying the presence of intracardial tumors, which indicated the presence of cardiac rhabdomyomas (Fig. 2). Ophthalmological examination clearly identified multiple nodules (Fig. 3). A detailed abdominal ultrasound did not identify any signs of TSC. Electrocardiogram revealed a sinus rhythm without cardiac arrhythmia and video electroencephalographic monitoring did not prompt a diagnosis of epileptic seizures. Mutation analysis of the TSC 1 and TSC 2 genes confirmed a diagnosis of TSC. A TSC2c.1642_1643insA [or TSC2p.K549fsX589; TSC2 normal gene reference is from NP_0,01070651.1 (https://www.ncbi. nlm.nih.gov/protein/116256350/)] frameshift mutation was identified, which terminated the translation of the encoded protein (Fig. 4). No mutations were identified in the TSC1 sequence.

Following diagnosis of TSC, the patient received antiepileptic drugs including Topamax ${ }^{\circledR}(3 \mathrm{mg} / \mathrm{kg} / \mathrm{day}$; Xian-Janssen Pharmaceutical Ltd., Xi'an, China), Depakin ${ }^{\circledR}$ (30 mg/kg/day; Sanofi S.A., Paris, France) and nitrazepam (1 mg/kg/day; Sigma-Aldrich; Merck KGaA, Darmstadt, Germany). However, this treatment did not alter the frequency of seizures. At the age of 3 months, the infant underwent treatment with $1 \mathrm{mg} /\left(\mathrm{m}^{2} /\right.$ day $)$ rapamycin orally to treat resistant epileptic seizures and the blood concentration of rapamycin

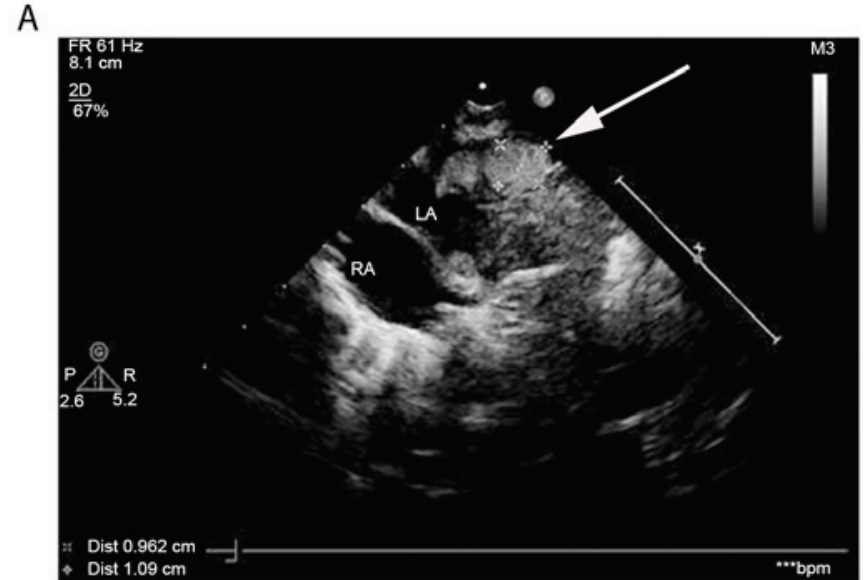

B

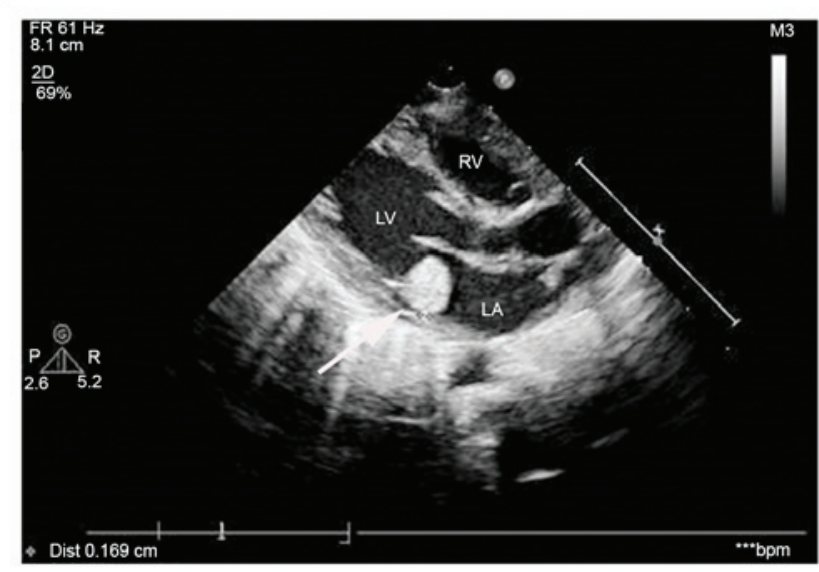

Figure 2. Echocardiographic images of cardiac rhabdomyomas located in (A) the LA, measuring $1.06 \times 0.89 \mathrm{~cm}$ and (B) the outlet of the RV, measuring $1.77 \times 1.68 \mathrm{~cm}$. Arrow indicates the cardiac rhabomyomas. LA, left atrium; $\mathrm{LV}$, left ventricle; RA, right atrium; RV, right ventricle; FR, frame rate; $2 \mathrm{D}$, two dimensional; dist, distance.

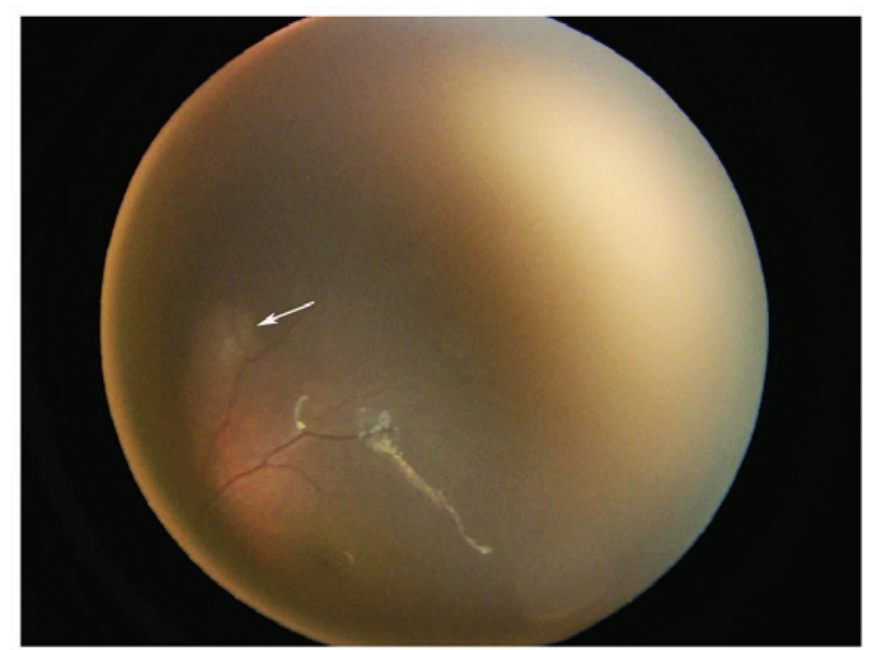

Figure 3. Ophthalmological examination revealing multiple clearly visible nodules.

was maintained at 5-10 $\mu \mathrm{g} / \mathrm{l}$, as measured using the Rapamycin ARCHITECT Sirolimus Reagent kit (cat. no. 72003M800) and the Abbott Architect i1000 (both Abbott Pharmaceutical Co., 


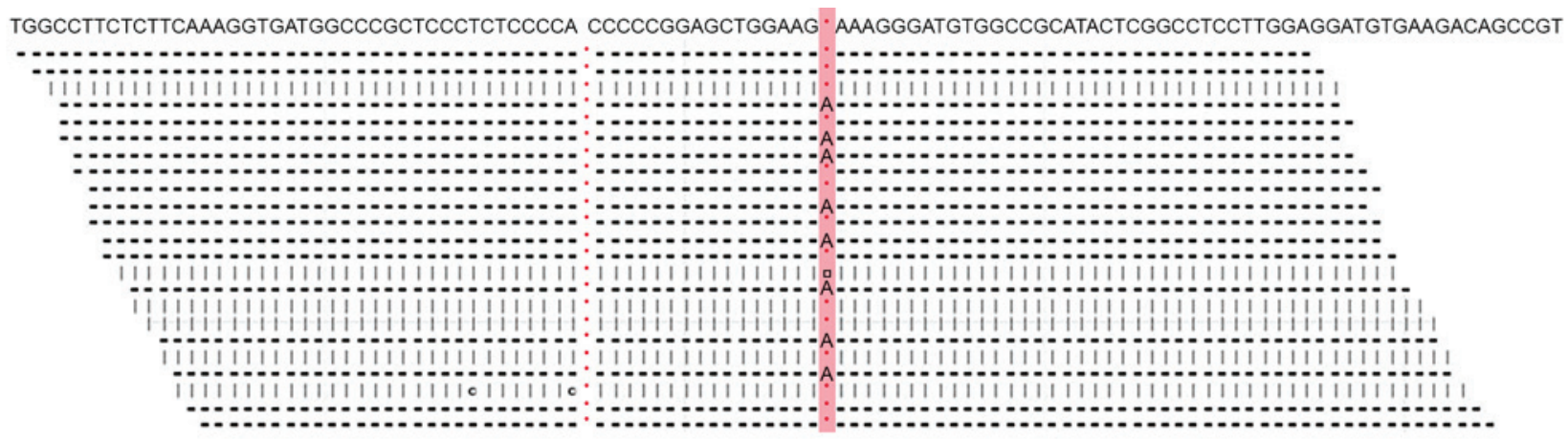

Figure 4. Genetic mutation analysis presenting a TSC2c.1642_1643insA frameshift mutation.
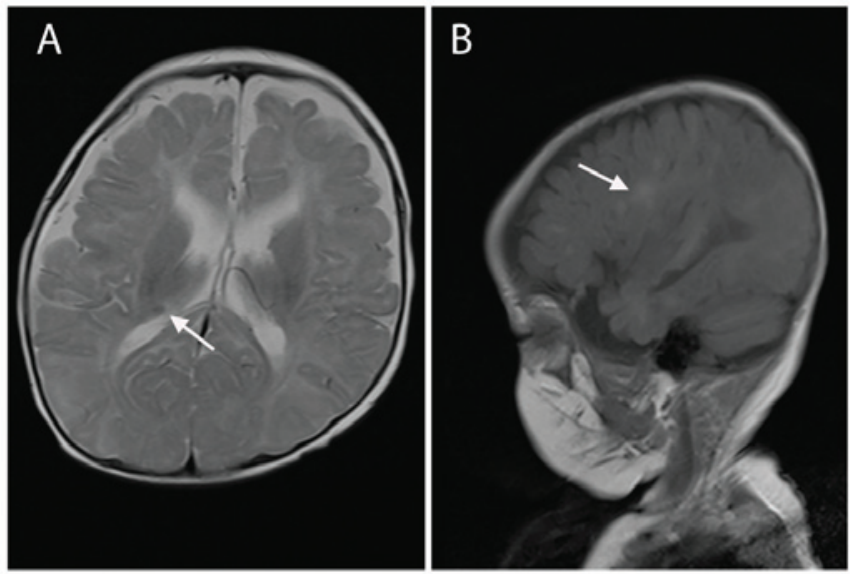

Figure 5. Brain MRI of the 6-month-old infant following treatment. (A) Axial plane and (B) sagittal plane MRI images of the infant presented in Fig. 1. Arrow indicated the subependymal nodules.

Ltd., Lake Bluff, IL, USA). During this period of 3 months, seizures and results of an electroencephalogram (EEG) were recorded every month and the results of the routine blood and urine tests, and liver and kidney function tests (including glutamic-pyruvic transaminase, normal range at 8-40 U/1 and serum creatinine, normal range at $15-77 \mu \mathrm{mol} / \mathrm{l}$ ) were normal. Echocardiography performed on the infant at the age of 6 months identified regression of multiple cardiac rhabdomyomas and MRI of the brain revealed a decrease in the size of cerebral lesions (Fig. 5). The results of the EEG were normal and the frequency of seizures decreased. However, the patient continued to exhibit mental retardation.

\section{Discussion}

A thorough search of literature published since 1990 (384 published manuscripts, including 98 reviews) was performed using PubMed (https://www.ncbi.nlm.nih. gov/pubmed) with the following key words: Tuberous sclerosis complex, newborn, neonates, neonatal, infants. Data from 36 infants aged $<4$ weeks who were diagnosed with TSC were included in the review. The clinical manifestations of TSC were present prior to birth in 8 patients $(22.22 \%)$, at birth in 13 patients (36.11\%) and by 4 weeks of age in 7 patients (19.44\%). Information regarding onset of TSC was not available for the remaining 8 patients included in the current review (22.22\%).
TSC was diagnosed at birth in 7 patients (19.44\%) and by 4 weeks of age in 29 patients $(80.56 \%)$. A greater number of males than females (ratio, 1.4:1) were diagnosed with TSC. There was a family history of TSC in 2 patients $(5.55 \%)$. The most common features at onset of TSC were cardiac rhabdomyomas $(36.11 \%)$, seizures $(19.44 \%)$, arrhythmia (16.67\%) and skin lesions (13.89\%) followed by renal cyst, opisthotonus, feeding difficulties and respiratory distress. A total of 34 neonates underwent brain MRI or computed tomography imaging and 2 neonates underwent a brain biopsy following mortality. Cortical tubes, subependymal nodules and subependymal giant cell astrocytomas were identified in 26 (72.22\%), 28 (77.78\%) and $5(13.89 \%)$ patients, respectively. Retinal hamartomas were detected in 5 neonates. The overall survival rate of neonates with TSC was $81 \%(21 / 26)$ and the duration of follow-up varied from 1 month to 4 years.

Cardiac rhabdomyomas were the most common initial symptom detected in neonates with TSC included in the current review and were identified in 13 neonates (36.11\%). Cardiac rhabdomyomas are the most prevalent heart tumors in neonates (15). It has been reported that $>80 \%$ of cardiac rhabdomyomas regress completely during infancy and early childhood (16). Depending on their size, location and number, cardiac rhabdomyomas cause serious cardiovascular complications, including intracavitary obstruction, diminished myocardial function and arrhythmia (17). Medical and/or surgical interventions are required for symptomatic patients with hemodynamically significant cardiac rhabdomyomas or a life-threatening arrhythmia (18). In the present review, 2 out of 7 neonates with arrhythmia succumbed following cardiac arrest but the other 5 neonates survived following effective antiarrhythmic treatment.

Neurological manifestations including seizures and mental retardation are the major factors for morbidity in patients with TSC (19). The current review indicated that $20 \%$ of neonates with TSC develop seizures in the first month of life. Early onset of epilepsy in TSC is strongly associated with mental retardation $(20,21)$. It has been demonstrated that antiepileptic treatment reduces the severity of epilepsy and risk of mental retardation in infants with TSC $(22,23)$. Brain lesions in TSC include cortical tubers, subependymal nodules (SEN), subependymal giant cell astrocytomas and white matter lesions (24). In the current review, cortical tubers and SEN were the two most common brain MRI manifestations in neonates with TSC. 
Cutaneous manifestations of TSC are easily identified and are present in $>90 \%$ of patients with TSC (25). Hypomelanotic macules may be present at birth, however they also may not appear until later in life (26). The ocular symptoms of TSC are retinal hamartomas and these occur in $40-50 \%$ of patients. Retinal hamartomas typically do not cause visual dysfunction (27) and ocular hamartomas rarely occur in neonates (28). However, in the current case, hypomelanotic macules and ocular hamartomas were present.

Renal lesions serve an important role in the course of TSC by impairing renal function (29). Renal cysts, angiomyolipomas and renal cell carcinomas are the most common renal lesions in patients with TSC $(30,31)$. Isaacs (32) reported that $13.2 \%$ of neonates and fetuses with TSC exhibit renal cysts. Polycystin 1, transient receptor potential channel interacting (PKD1) is the major gene responsible for autosomal dominant polycystic kidney disease. The TSC2 gene lies adjacent to PKD1, suggesting that PKD1 serves a role in the etiology of renal cystic disease in TSC (33). Deletion of the TSC2 and PKD1 genes is associated with a severe polycystic phenotype and this occurs in $2 \%$ of patients with TSC (34).

TSC is caused by mutations in either of the two tumor suppressor genes, TSC1, which encodes hamartin (35) and TSC2, which encodes tuberin (36). TSC1 and TSC2 inhibit the mechanistic target of the mTOR-mediated signaling pathway, thus preventing cell growth and cell cycle progression (37). Dysfunction of TSC1/TSC2, which may be caused by a mutation, results in the loss of control of mTOR signaling and subsequently causes cancer. A novel TSC2 mutation was present in the current case report. The earlier diagnosis of patients with TSC 2 mutations may be beneficial for reducing the severity of symptoms with earlier intervention (38). Rapamycin inhibits the activation of the mTOR signaling pathway and has been used to treat patients with TSC (39). Several studies have demonstrated successful regression of lesions in the skin, brain, and kidney (40-42). Canpolat et al (13) demonstrated that rapamycin effectively controls epilepsy without causing any marked side effects in children with TSC. However, to the best of our knowledge, there have been no studies in English investigating the effect of rapamycin on epilepsy in neonates and the safety of rapamycin in patients $<18$ years of age, particularly in infant and neonates, remains unknown (43). The patient in the current case study received rapamycin treatment and had a good prognosis, experiencing regression of cardiac rhabdomyomas and controlled seizures. Therefore, the current case report indicated that rapamycin treatment for TSC caused by a TSC 2 mutation was therapeutically beneficial and may be beneficial in treating other disorders caused by abnormal mTOR signaling, such as cancer.

The current study demonstrates that cardiac rhabdomyomas, seizures and skin lesions are well established markers for TSC in neonates. MRI scans of the brain and genetic screening of TSC 1 and TSC 2 genes may facilitate an early diagnosis of TSC.

\section{Acknowledgements}

The present study was supported by the Science \& Technology Bureau of Zhejiang Province (Zhejiang, China; grant no. 2015C31101).

\section{References}

1. Curatolo P and Maria BL: Tuberous sclerosis. Handb Clin Neurol 111: 323-331, 2013.

2. Crino PB, Nathanson KL and Henske EP: The tuberous sclerosis complex. N Engl J Med 355: 1345-1356, 2006.

3. Wortmann SB, Reimer A, Creemers JW and Mullaart RA: Prenatal diagnosis of cerebral lesions in Tuberous sclerosis complex (TSC). Case report and review of the literature. Eur J Paediatr Neurol 12: 123-126, 2008.

4. Lee KA, Won HS, Shim JY, Lee PR and Kim A: Molecular genetic, cardiac and neurodevelopmental findings in cases of prenatally diagnosed rhabdomyoma associated with tuberous sclerosis complex. Ultrasound Obstet Gynecol 41: 306-311, 2013.

5. Shepherd CW, Gomez MR, Lie JT and Crowson CS: Causes of death in patients with tuberous sclerosis. Mayo Clin Proc 66: 792-796, 1991.

6. Saxena A and Sampson JR: Epilepsy in Tuberous Sclerosis: Phenotypes, mechanisms and treatments. Semin Neurol 35: 269-276, 2015.

7. Pascual-Castroviejo I: Neurosurgical treatment of tuberous sclerosis complex lesions. Childs Nerv Syst 27: 1211-1219, 2011.

8. Krueger DA and Northrup H; International Tuberous Sclerosis Complex Consensus Group: Tuberous sclerosis complex surveillance and management: Recommendations of the 2012 International Tuberous Sclerosis Complex Consensus Conference. Pediatr Neurol 49: 255-265, 2013.

9. Go CY, Mackay MT, Weiss SK, Stephens D, Adams-Webber T, Ashwal S and Snead OC III; Child Neurology Society; American Academy of Neurology: Evidence-based guideline update: Medical treatment of infantile spasms. Report of the Guideline Development Subcommittee of the American Academy of Neurology and the Practice Committee of the Child Neurology Society. Neurology 78: 1974-1980, 2012.

10. Press Announcements-FDA approves Afinitor for non-cancerous kidney tumors caused by rare genetic disease. https:// elbiruniblogspotcom.blogspot.ca/2012/04/press-announcements-fda-approves_27.html. Accessed April 27, 2012.

11. French JA, Lawson JA, Yapici Z, Ikeda H, Polster T, Nabbout R, Curatolo P, de Vries PJ, Dlugos DJ, Berkowitz N, et al: Adjunctive everolimus therapy for treatment-resistant focal-onset seizures associated with tuberous sclerosis (EXIST-3): A phase 3, randomised, double-blind, placebo-controlled study. The Lancet 388: 2153-2163, 2016.

12. AG Novartis International: Novartis drug Votubia ${ }^{\circledR}$ receives EU approval to treat refractory partial-onset seizures in patients with TSC. https://www.novartis. com/news/media-releases/novartis-drug-votubiar-receives-eu-ap proval-treat-refractory-partial-onset. Accessed January, 312017

13. Canpolat M, Per H, Gumus H, Yikilmaz A, Unal E, Patiroglu T, Cinar L, Kurtsoy A and Kumandas S: Rapamycin has a beneficial effect on controlling epilepsy in children with tuberous sclerosis complex: Results of 7 children from a cohort of 86. Childs Nerv Syst 30: 227-240, 2014.

14. Gipson TT, Gerner G, Srivastava S, Poretti A, Vaurio R, Hartman A and Johnston MV: Early Neurodevelopmental Screening in TSC: A Potential Window of Opportunity. Pediatr Neurol 51: 398-402, 2014.

15. Isaacs H Jr: Fetal and neonatal cardiac tumors. Pediatr Cardiol 25: 252-273, 2004.

16. Bader RS, Chitayat D, Kelly E, Ryan G, Smallhorn JF, Toi A and Hornberger LK: Fetal rhabdomyoma: Prenatal diagnosis, clinical outcome, and incidence of associated tuberous sclerosis complex. J Pediatr 143: 620-624, 2003.

17. Verhaaren HA, Vanakker O, De Wolf D, Suys B, Francois K and Matthys D: Left ventricular outflow obstruction in rhabdomyoma of infancy: Meta-analysis of the literature. J Pediatr 143: 258-263, 2003.

18. Stiller B, Hetzer R, Meyer R, Dittrich S, Pees C, Alexi-Meskishvili V and Lange PE: Primary cardiac tumours: When is surgery necessary? Eur J Cardiothorac Surg 20: 1002-1006, 2001.

19. Napolioni V, Moavero R and Curatolo P: Recent advances in neurobiology of Tuberous Sclerosis Complex. Brain Dev 31: 104-113, 2009.

20. Chu-Shore CJ, Major P, Camposano S, Muzykewicz D and Thiele EA: The natural history of epilepsy in tuberous sclerosis complex. Epilepsia 51: 1236-1241, 2010. 
21. Curatolo P, Aronica E, Jansen A, Jansen F, Kotulska K, Lagae L, Moavero R and Jozwiak S: Early onset epileptic encephalopathy or genetically determined encephalopathy with early onset epilepsy? Lessons learned from TSC. Eur J Paediatr Neurol 20: 203-211, 2016.

22. Jozwiak S, Kotulska K, Domańska-Pakieła D, Lojszczyk B Syczewska M, Chmielewski D, Dunin-Wasowicz D, Kmieć T, Szymkiewicz-Dangel J, Kornacka M, et al: Antiepileptic treatment before the onset of seizures reduces epilepsy severity and risk of mental retardation in infants with tuberous sclerosis complex. Eur J Paediatr Neurol 15: 424-431, 2011.

23. Cusmai R, Moavero R, Bombardieri R, Vigevano $F$ and Curatolo P: Long-term neurological outcome in children with early-onset epilepsy associated with tuberous sclerosis. Epilepsy Behav 22: 735-739, 2011

24. Mizuguchi M and Takashima S: Neuropathology of tuberous sclerosis. Brain Dev 23: 508-515, 2001.

25. Cardis MA and DeKlotz CM: Cutaneous manifestations of tuberous sclerosis complex and the paediatrician's role. Arch Dis Child 102: 858-863, 2017.

26. Hake S: Cutaneous manifestations of tuberous sclerosis. Ochsner J 10: 200-204, 2010.

27. Schwartz RA, Fernández G, Kotulska K and Jóźwiak S: Tuberous sclerosis complex: Advances in diagnosis, genetics and management. J Am Acad Dermatol 57: 189-202, 2007.

28. Knopke S, Olze H, Becker ET, Manthey D, Lindig-Knopke C, Jöhrens K, Stölzel K and Böttcher A: Head and neck hamartomas: 10 years of experience at the Charité-University Medical Center Berlin. HNO 63: 552-556, 2015.

29. Kingswood JC, Bissler JJ, Budde K, Hulbert J, Guay-Woodford L, Sampson JR, Sauter M, Cox J, Patel U, Elmslie F, et al: Review of the Tuberous Sclerosis Renal Guidelines from the 2012 Consensus Conference: Current Data and Future Study. Nephron 134: 51-58, 2016.

30. Korula S, Ekbote A, Kumar N, Danda S, Agarwal I and Chaturvedi S: Renal manifestations of tuberous sclerosis among children: An Indian experience and review of the literature. Clin Kidney J 7: 134-137, 2014.

31. Rouviere O, Nivet H, Grenier N, Zini L and Lechevallier E: Kidney damage due to tuberous sclerosis complex: Management recommendations. Diagn Interv Imaging 94: 225-237, 2013.

32. Isaacs H: Perinatal (fetal and neonatal) tuberous sclerosis: A review. Am J Perinatol 26: 755-760, 2009.

33. Martignoni G, Bonetti F, Pea M, Tardanico R, Brunelli M and Eble JN: Renal disease in adults with TSC2/PKD1 contiguous gene syndrome. Am J Surg Pathol 26: 198-205, 2002.
34. Ismail NF, Nik Abdul Malik NM, Mohseni J, Rani AM, Hayati F, Salmi AR, Narazah MY, Zabidi-Hussin ZA, Silawati AR, Keng WT, et al: Two novel gross deletions of TSC2 in Malaysian patients with tuberous sclerosis complex and TSC2/PKD1 contiguous deletion syndrome. Jpn J Clin Oncol 44: 506-511, 2014.

35. van Slegtenhorst M, de Hoogt R, Hermans C, Nellist M, Janssen B, Verhoef S, Lindhout D, van den Ouweland A, Halley D, Young J, et al: Identification of the tuberous sclerosis gene TSC1 on chromosome 9q34. Science 277: 805-808, 1997.

36. European Chromosome 16 Tuberous Sclerosis Consortium: Identification and characterization of the tuberous sclerosis gene on chromosome 16. Cell 75: 1305-1315, 1993.

37. Kwiatkowski DJ: Rhebbing up mTOR: New insights on TSC1 and TSC2, and the pathogenesis of tuberous sclerosis. Cancer Biol Ther 2: 471-476, 2003.

38. Dabora SL, Jozwiak S, Franz DN, Roberts PS, Nieto A, Chung J, Choy YS, Reeve MP, Thiele E, Egelhoff JC, et al: Mutational analysis in a cohort of 224 tuberous sclerosis patients indicates increased severity of TSC2, compared with TSC1, disease in multiple organs. Am J Hum Genet 68: 64-80, 2001.

39. Kim WS: Mammalian target of rapamycin inhibitors for treatment in tuberous sclerosis. Korean J Pediatr 54: 241-245, 2011.

40. Franz DN, Leonard J, Tudor C, Chuck G, Care M, Sethuraman G, Dinopoulos A, Thomas G and Crone KR: Rapamycin causes regression of astrocytomas in tuberous sclerosis complex. Ann Neurol 59: 490-498, 2006.

41. Hofbauer GF, Marcollo-Pini A, Corsenca A, Kistler AD, French LE, Wuthrich RP and Serra AL: The mTOR inhibitor rapamycin significantly improves facial angiofibroma lesions in a patient with tuberous sclerosis. Br J Dermatol 159: 473-475, 2008.

42. Micozkadioglu H, Koc Z, Ozelsancak R and Yildiz I: Rapamycin therapy for renal, brain, and skin lesions in a tuberous sclerosis patient. Ren Fail 32: 1233-1236, 2010.

43. Rapamune: Prescribing information. United States Food and Drug Administration. Wyeth Pharmaceuticals, Inc. May, 2015. https://www.accessdata.fda.gov/drugsatfda_docs/label/2015/021 083s058,021110s075lbl.pdf. Accessed May 28, 2016. 